\title{
Correction to: How to Be RAD: Repeated Acquisition Design Features that Enhance Internal and External Validity
}

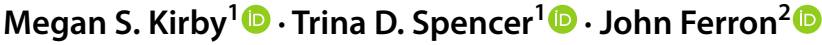

Published online: 19 October 2021

๑) Association for Behavior Analysis International 2021

\section{Correction to: Perspectives on Behavior Science (2021) 44:389-416 https://doi.org/10.1007/s40614-021-00301-2}

This article was updated to correct the spelling of Micheal Sandbank in the quote attribution on the second page of the article.

Publisher's Note Springer Nature remains neutral with regard to jurisdictional claims in published maps and institutional affiliations.

The original article can be found online at https://doi.org/10.1007/s40614-021-00301-2.

Megan S. Kirby

megankirby@usf.edu

1 College of Behavioral and Community Sciences, University of South Florida, 13301 Bruce B. Downs Blvd. MHC 1702, Tampa, FL 33612, USA

2 College of Education, University of South Florida, Tampa, FL, USA 